\title{
Effects of training to implement new working methods to reduce knee strain in floor layers. A two- year follow-up
}

\author{
L K Jensen, C Friche
}

Department of Occupational Medicine, Region Hospital Skive, Denmark

Correspondence to: Dr L K Jensen, Department of Occupational Medicine, Region Hospital Skive, Resenvej 25, DK7800 Skive, Denmark; lilli.kirkeskov.jensen@ sygehusviborg.dk

Accepted 11 May 2007 Published Online First 23 May 2007

\section{ABSTRACT}

Objectives: Follow-up study after two years to measure the effects of an implementation strategy consisting of information, education and training in the use of new tools and working-methods for the purpose of reducing knee strain and knee complaints in floor layers.

Methods: Training of floor layers $(n=292)$ in using new working methods was evaluated by questionnaires during the courses. Two years later, this follow-up included questionnaires for the course participants $(n=216)$ and a control group of floor layers (not trained on courses) $(\mathrm{n}=454)$

Results: Two years after training, 38\% used the new working methods weekly or daily compared to $37 \%$ three months after the courses, and $10 \%$ before. Among controls, only $16 \%$ had used the new working methods weekly or daily. The risk of knee complaints $>30$ days (OR 2.46, 95\% Cl 1.03 to 5.83) or locking of the knees (OR 2.89, 95\% Cl 1.11 to 7.5 ) was more than double among floor layers who had used the new workingmethods for less than one year compared to those who had used them more. The results were adjusted for age, body mass index, and stress. The reduction in more severe knee complaints was greatest if floor layers started to use the new working methods before they developed knee problems. Other musculoskeletal complaints did not increase.

Conclusion: This indicates that, within a two-year perspective, the implementation strategy to introduce new working methods in the floor laying trade has been effective; the number of floor layers using the new working-methods has increased, and severe knee problems have reduced.

Earlier studies have shown that floor layers spend more than half their working day in knee-straining working positions ${ }^{1-4}$ and have an increased frequency of knee disorders compared with other trades in the construction industry. ${ }^{2-6}$ In Denmark, around 900 floor layers are members of the trade union, which is about $90 \%$ of all floor layers in Denmark. Floor and carpet layers (collectively referred to as floor layers in this paper) install linoleum, carpet and vinyl floorings. Their work tasks include priming, grinding, filling, gluing and welding. Nearly all floor layers in Denmark use knee pads (98\%) and this frequency of use was equal before and after the courses. During recent years, new tools have been introduced which make it possible to carry out some of the job tasks, such as gluing and welding, from a standing position. In spite of campaigns and the development of the new tools, a study from 2000 showed that only
$13 \%$ of floor layers used the new working methods during the previous 12 months. The floor layers reported that the reason for the lack of change was that the new methods required instruction and that educational training was necessary. In general, the floor layers would only take suggestions from people who were experienced in their trade. These results agree with the findings of other studies. ${ }^{8-10}$

From 2002-3, 292 floor layers were therefore trained in using new working methods. The effects were evaluated three months after training by using questionnaires, interviews and assessment of the quality and productivity of the work tasks done using both the conventional and new working methods. ${ }^{11}$

The main objective of this part of the study was to investigate, during a two-year follow-up, whether the implementation strategy had a longterm effect on the use of the new working methods and on musculoskeletal complaints when compared with using the previous conventional working methods. The hypothesis was that, at follow-up, it would be found that the implementation strategy: (1) had permanently increased the use of the new working methods among course participants; (2) resulted in the new working methods spreading to floor layers who did not participate in training courses; and (3) had reduced the frequency and amount of knee complaints and not produced new health problems among the floor layers who use the new working methods often.

This objective was put into effect by focusing the study on the following research questions:

1. Was the frequency of floor layers using the new working methods still the same after a period of two years?

2. Did the use of new working methods spread to floor layers who did not participate in courses?

3. Did the use of the new working methods reduce musculoskeletal complaints in the knee when comparing floor layers who changed their working methods with those who did not?

4. Did the use of the new working methods result in other health problems such as musculoskeletal complaints from, for example, the elbows, wrists and back?

5. In the data of the 2003 study, could predictors be found of the presence or absence in 2005 of sustained more serious knee problems? 


\section{METHODS}

\section{Study population and design}

The study had two parts: (1) a cross-sectional study which investigated whether implementation of a new working method was successful by comparing floor layers who participated in courses in 2003 ( $n=216$ ) with controls who did not participate ( $n=454)$; and (2) a follow-up study of floor layers who participated in courses in $2003(n=216)$. The total population and the study population are shown in figure 1.

\section{Intervention}

The implementation strategy consisted of the following phases:

1. Giving information to the workers and their employers about the new tools (where to buy and how to use them).

2. Providing information to the workers about the tools and the health risks, comparing the conventional and the new working methods.

3. Showing the new working methods to the floor layers at after-work meetings around the whole country (thereby persuading the floor layers to use them).

4. Donation of the tools free of charge to the floor layers if they participated in a two-day course, thereby both facilitating the intervention and enabling floor layers to continue using the new working methods after the courses.

5. Training in using the tools on a two-day course.

6. Providing experience of using the new working methods during the training.

In 2002, eight regional meetings were arranged by the trade union and the employers' association to introduce the new working methods. Four courses were arranged in October 2002, with a total of 38 floor layers as participants. A specialist teacher with knowledge of using the new working methods was used at these courses. The courses were used as pilots.

A total of 10 floor layers participated in a two-week course in January 2003 to become supervisors. The course included training in the new working techniques, communication and teaching skills, educational training and ergonomics.

From February to June 2003, 43 courses were arranged, with a total of 254 participants. The 10 floor layers who had had the
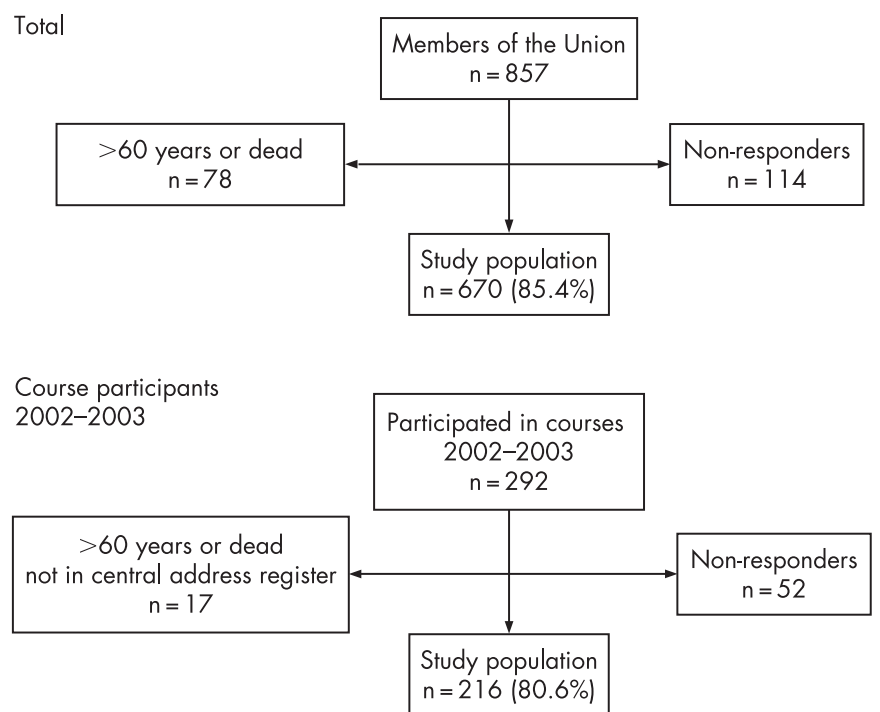

Figure 1 Questionnaire study. Description of the material for the studies. Total population, study population. Total and course participants 2002-3. two-week supervisor-courses were used as teachers at the courses. The employers' association made contacts with the employers to get enough floor layers to participate. The floor layers participating in the courses were therefore not randomly selected but were chosen if they were interested and if their employers supported participation.

The programme for the courses comprised theoretical instruction in the different kinds of new working methods, and theoretical and practical instruction in the use of the new working methods. All participants were provided with a complete set of tools which made it possible to carry out from an upright position the job tasks of gluing, filling, welding, upcutting, and cutting of welding wire. The system is based on a telescopic stick, an intercostals fitting, and special fittings for the specific job tasks. Figure 2 shows the work tasks of gluing and filling-in material being carried out both traditionally and from an upright work position. The floor layers were instructed to walk backwards and/or forwards while they held the stick close in front of the trunk. The set of tools was provided to the floor layers free of charge, which they could then keep after the course. The sets of tools were purchased with funding provided by the trade union and the employers' association. The floor layers were paid for the hours spent training; this was made possible by funding from a government grant for the courses.

\section{Questionnaire study}

During two-day courses in 2003, the floor layers filled out questionnaires. These included questions about musculoskeletal health problems from the Nordic Health Questionnaire, ${ }^{12}$ psychological conditions, and their experience with the new working methods. In the case of musculoskeletal problems, they reported if the complaints had been present during the previous 12 months. For knee complaints, they were asked to report further if the complaints had been present daily or for more than 30 days during previous 12 months. The degree of knee complaints was reported on an ordinal categorical scale ranging from 0 (no complaints) to 9 (severe complaints).

Follow-ups after three months and after two years were carried out by sending out questionnaires to the participants who took part in the first questionnaire study. In the event of lack-of-response, the questionnaire was, if possible, filled out by a structured telephone interview. The questionnaire included the same questions as the 2003 studies, and floor layers who reported musculoskeletal complaints during the previous 12 months were asked to report, with a score, whether the knee pain was reduced or increased. In addition, a questionnaire was sent in 2005 to the rest of the floor layers who were members of the Danish trade union. This group was defined as a control group in relation to the participants in the training courses in 2003.

\section{Statistical analysis}

The frequency of floor layers using the new working methods at the beginning of the study and after two years was analysed by comparing floor layers who participated in courses in 2003 $(\mathrm{n}=216)$ and who answered questionnaires both at the courses in 2003 and again in 2005. The spread of the working methods to the floor layers who did not participate in courses was analysed by comparing results from the course participants with the controls who did not participate $(n=454)$. The frequency of musculoskeletal complaints was compared for floor layers who participated in courses with the control group (results from questionnaires, 2005) and it was also compared for floor layers 
Figure 2 (A) Floor layers. Gluing; working traditionally (left), and using new (right) working methods. (B) Floor layers. Filling; working traditionally (left), and using new (right) working methods.
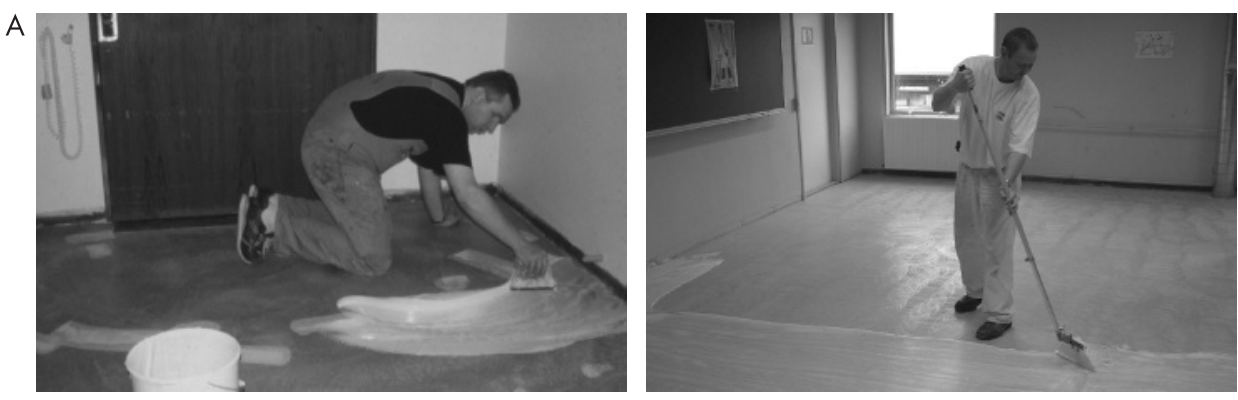

B

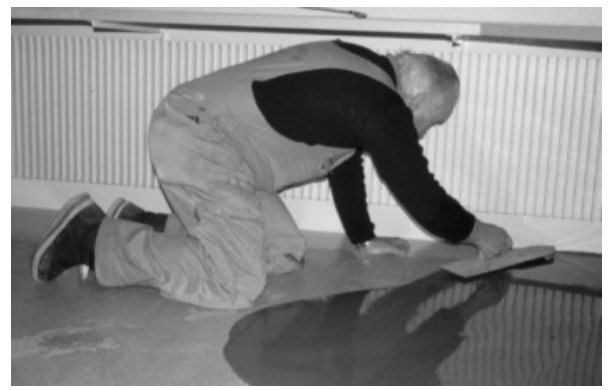

who had used the new working methods and those who did not. The analyses were made by using $\chi^{2}$ test $(p<0.05 ; 95 \%$ CIs) for simple $2 \times 2$ tables. Analysing for predictors in the 2003 study for sustained knee complaints which were subsequently reported in 2005 was done by using a logistic regression model (binomial) with adjustment for age, body mass index (BMI), and self-reported stress for the following outcome measures: (1) knee complaints for $>30$ days during the previous 12 months; (2) locking of the knee; (3) knee complaint (moderate to severe); (4) decrease in knee pain; (5) difficulties in carrying out the work as a result of knee troubles; (6) sick leave; and (7) selfreported stress.

Age was divided into bands of $<35$ years and 35 years or more. Body mass index (weight $(\mathrm{kg}) /$ height $^{2}$ ) was divided into $<27$ and 27 or more. Stress was divided into two groups "no or light" and "moderate or severe". Knee pain was reported on an ordinal categorical scale from 0-9 where 0 represents "no pain" and 9 "severe pain". The results were divided into two groups: no or light pain (score $0-3$ ) and moderate or severe pain (score 4-9). If the floor layers reported knee pain, they were also asked if the knee pain was "the same", "worse" or "less" than in 2003. In the test "less" pain was compared to "no", "the same" or "worse" pain. For testing, SPSS version 10.0 was used.

\section{RESULTS}

A total of 670 floor layers participated in the 2005 questionnaire study (response rate $85 \%$ ). Of that total, 280 (41.7\% of the participants) did not respond to the posted questionnaire, but

Table 1 Demographic and anthropometrical characteristics of the study population

\begin{tabular}{lll}
\hline & $\begin{array}{l}\text { Course participants } \\
(\mathbf{n}=\mathbf{2 1 6}), \text { mean (range) }\end{array}$ & $\begin{array}{l}\text { Controls (n=454), } \\
\text { mean (range) }\end{array}$ \\
\hline $\begin{array}{l}\text { Age (years) } \\
\text { Seniority (duration of employment }\end{array}$ & $38.5(19-59)$ & $34.3(17-59)$ \\
in the trade: years) & $16.7(0-45)$ & $13.1(0-45)$ \\
Seniority with the same employer & $10.4(0-45)$ & $7.6(0-38)$ \\
BMl (weight/height $\left.{ }^{2}\right)$ & $25.7(19-41)$ & $25.2(17-39)$ \\
Weight (kg) & $83.4(57-140)$ & $82.0(53-120)$ \\
Height & $180(166-207)$ & $180(164-198)$ \\
\hline
\end{tabular}

subsequently answered the questionnaires via a structured telephone interview. A total of 216 floor layers completed the questionnaire both during the courses in 2003 and two years later in 2005 (response rate at follow-up, 81\%). All participants were male, which reflected the gender distribution in the trade. Compared to controls, course participants were slightly older, and had higher seniority in the trade. The basic characteristics of the study population are shown in table 1.

\section{Use of new working methods}

Table 2 shows use of the new working methods before the courses in 2003, at the three-month follow-up after the courses, and at two-year follow-up in 2005. The number of floor layers using the new working methods was nearly the same three months after the courses (weekly $27.8 \%$, and daily $9.3 \%$ ) and at the follow-up in 2005 (weekly $29.6 \%$ and daily 8.8\%). For floor layers who did not participate in courses in 2003, the frequency of using the new working methods was lower (weekly $12.3 \%$, daily $3.5 \%$ ) compared to the frequency among floor layers participating in the courses.

Floor layers who participated in courses reported that the new working methods were easy to use, that the work went faster, and that they suffered fewer health problems. Floor layers who had not used the new working methods reported that they wanted to use the traditional working method or that the work task had been too small, as shown in table 2 .

\section{Musculoskeletal complaints}

Table 2 shows knee complaints during the previous 12 months or more than 30 days during the previous 12 months for floor layers, before and after courses. These are compared with controls, and with floor layers who had never used the new working methods, had used them occasionally, weekly or daily. Overall, neither floor layers who had participated in courses in 2003 nor those controls who had used the new working methods weekly or daily had a reduced frequency of reported knee complaints compared with floor layers who had never or occasionally used the new working methods.

Floor layers who had used the new working methods for less than one year had an increased frequency of knee complaints 
Table 2 Rates of use of new working methods, reasons for use/non-use, and self-reported knee complaints. Results are from the questionnaires in 2003 and 2005 for course participants $(n=216)$ and controls ( $n=454$ )

\begin{tabular}{|c|c|c|c|c|c|}
\hline & \multicolumn{2}{|l|}{2003} & \multicolumn{3}{|l|}{2005} \\
\hline & $\begin{array}{l}\text { Before } \\
\text { training } \\
(n=216) \\
n(\%)\end{array}$ & $\begin{array}{l}3 \text { months } \\
\text { after training } \\
(n=216) \\
n(\%)\end{array}$ & $\begin{array}{l}2 \text { years after } \\
\text { training } \\
(\mathrm{n}=216) \\
\mathrm{n}(\%)\end{array}$ & $\begin{array}{l}\text { Control } \\
(n=454) \\
n(\%)\end{array}$ & $\begin{array}{l}\text { Total } \\
(n=670) \\
n(\%)\end{array}$ \\
\hline & \multicolumn{5}{|c|}{ Experience of new working methods: use/no use } \\
\hline Have not used the tools (total) & $107(49.5)$ & & $40(18.5)$ & $238(52.4)$ & $278(41.5)$ \\
\hline Not enough instruction & $51(23.6)$ & & $0(0)$ & $15(3.3)$ & $15(2.2)$ \\
\hline Work task too small & $27(12.5)$ & & $24(11.1)$ & $72(15.9)$ & $96(14.3)$ \\
\hline No time for training & $19(8.8)$ & & $6(2.8)$ & $26(5.7)$ & $32(4.8)$ \\
\hline Takes too long & $11(5.1)$ & & $2(0.9)$ & $18(4.0)$ & $20(3.0)$ \\
\hline Tools not good enough & $8(3.7)$ & & $2(0.9)$ & $10(2.2)$ & $12(1.8)$ \\
\hline Want to do as usual & $4(1.9)$ & & $12(5.6)$ & $84(18.5)$ & $96(14.3)$ \\
\hline Have used the tools (total) & $107(49.5)$ & & $176(81.5)$ & $216(47.6)$ & $392(58.5)$ \\
\hline Work goes faster & $64(29.6)$ & & $115(53.2)$ & $113(24.9)$ & $228(34.0)$ \\
\hline Easy to use & $52(24.1)$ & & $130(60.2)$ & $136(30.0)$ & $266(39.7)$ \\
\hline Fewer health problems & $39(18.1)$ & & $104(48.1)$ & $93(20.5)$ & $197(29.4)$ \\
\hline Not enough instruction & $19(8.8)$ & & $2(0.9)$ & $23(5.1)$ & $25(3.7)$ \\
\hline Work task too small & $12(5.6)$ & & $55(25.5)$ & $72(15.9)$ & $127(19.0)$ \\
\hline Want to do as usual & $2(0.9)$ & & $5(2.3)$ & $15(3.3)$ & $20(3.0)$ \\
\hline \multicolumn{6}{|l|}{ Use of new working methods } \\
\hline Never & $107(49.5)$ & $18(8.3)$ & $39(18.1)$ & $242(53.3)$ & $281(41.9)$ \\
\hline Occasionally & $73(33.8)$ & $77(35.6)$ & $92(42.6)$ & $128(28.2)$ & $220(32.8)$ \\
\hline Weekly & $15(6.9)$ & $60(27.8)$ & $64(29.6)$ & $56(12.3)$ & $120(17.9)$ \\
\hline Daily & $6(2.8)$ & $20(9.3)$ & $19(8.8)$ & $16(3.5)$ & $35(5.2)$ \\
\hline Missing & $15(6.9)$ & $41(19.0)$ & $2(0.9)$ & $12(2.6)$ & $14(2.1)$ \\
\hline Never & & & $33(15.3)$ & $242(53.3)$ & $275(41.0)$ \\
\hline$<1$ year & & & $42(19.4)$ & $102(22.4)$ & $144(21.5)$ \\
\hline$\geqslant 1$ year & & & $140(64.8)$ & $101(22.3)$ & $241(36.1)$ \\
\hline \multirow[t]{2}{*}{ Missing } & & & $1(0.5)$ & $9(2.0)$ & $10(1.5)$ \\
\hline & \multicolumn{5}{|c|}{ Knee complaints during the previous 12 months } \\
\hline \multicolumn{6}{|l|}{ Use of new working methods } \\
\hline Never & 21/39 (53.8) & $16 / 30(53.3$ & 23/39 (59.0) & 139/242 (57.4) & $162 / 281(57.7)$ \\
\hline Occasionally & $53 / 92(57.6)$ & $47 / 76(61.8)$ & $59 / 92(64.1)$ & $83 / 128(64.8)$ & $142 / 220(64.5)$ \\
\hline Weekly & $34 / 63(54.0)$ & $25 / 51(49.0)$ & $41 / 64(64.1)$ & $32 / 56(57.1)$ & $73 / 120(60.8)$ \\
\hline \multirow[t]{2}{*}{ Daily } & $7 / 19(36.8)$ & $8 / 15(53.3)$ & $10 / 19(52.6)$ & $9 / 16(56.3)$ & $19 / 35(54.3)$ \\
\hline & $p=0.434^{*}$ & $p=0.535^{*}$ & $p=0.765^{*}$ & $p=0.543^{*}$ & $p=0.388^{*}$ \\
\hline Never & 18/33 (54.5) & & $18 / 33(54.5)$ & $135 / 242(55.8)$ & $153 / 273(56.0)$ \\
\hline$<1$ year & $24 / 42(57.1)$ & & $32 / 42(76.2)$ & 73/102 (71.6) & $105 / 144(72.9)$ \\
\hline \multirow[t]{3}{*}{$\geqslant 1$ year } & $74 / 139(53.2)$ & & $84 / 140(60.0)$ & $56 / 101$ (55.4) & $140 / 241(58.1)$ \\
\hline & $p=0.905^{*}$ & & $p=0.100^{*}$ & $p=0.019$ & $p=0.002$ \\
\hline & \multicolumn{5}{|c|}{ Knee complaints $>30$ days during previous 12 months } \\
\hline \multicolumn{6}{|l|}{ Use of new working methods } \\
\hline Never & 15/39 (38.5) & & 14/39 (35.9) & 49/242 (20.2) & $63 / 280(22.5)$ \\
\hline Occasionally & $34 / 92$ (37.0) & & 22/92 (23.9) & $36 / 128(28.1)$ & $58 / 219(26.5)$ \\
\hline Weekly & 22/61 (36.1) & & $11 / 64$ (17.2) & 15/56 (26.8) & 26/119 (21.8) \\
\hline \multirow[t]{2}{*}{ Daily } & $5 / 19(26.3)$ & & $4 / 19(21.1)$ & 3/16 (18.8) & $7 / 35(20.0)$ \\
\hline & $p=0.820^{*}$ & & $p=0.172^{*}$ & $p=0.304^{* *}$ & $p=0.647^{*}$ \\
\hline Never & 12/33 (35.4) & & $10 / 33(30.3)$ & $50 / 242(20.7)$ & $60 / 271(22.1)$ \\
\hline$<1$ year & 16/41 (39.0) & & $14 / 42$ (33.3) & $34 / 102$ (33.3) & 48/144 (33.3) \\
\hline \multirow[t]{3}{*}{$\geqslant 1$ year } & 48/137 (35.0) & & 27/140 (19.3) & 19/101 (18.8) & 46/240 (19.2) \\
\hline & $p=0.896^{*}$ & & $p=0.104^{*}$ & $p=0.022^{*}$ & $p=0.005^{*}$ \\
\hline & \multicolumn{5}{|c|}{ Reduced $\dagger$ knee complaints during the previous 12 months } \\
\hline \multicolumn{6}{|l|}{ Use of new working methods } \\
\hline Never & & $1 / 29(3.4)$ & $0 / 39(0)$ & $18 / 242(7.4)$ & $18 / 281(6.4)$ \\
\hline Occasionally & & $14 / 75(18.7)$ & $5 / 92(5.5)$ & $11 / 128(8.6)$ & $16 / 220(7.3)$ \\
\hline Weekly & & $12 / 50(24.0)$ & $8 / 64(12.5)$ & $8 / 56(14.3)$ & $16 / 120(13.3)$ \\
\hline \multirow[t]{2}{*}{ Daily } & & $4 / 14(28.6)$ & $5 / 19(26.3)$ & $0 / 16(0)$ & $5 / 35(14.3)$ \\
\hline & & $p=0.109^{*}$ & $p=0.003^{*}$ & $\mathrm{p}=0.234^{*}$ & $p=0.069^{*}$ \\
\hline Never & & $1 / 23(4.3)$ & $0 / 33(0)$ & $15 / 242(6.2)$ & $15 / 271(5.5)$ \\
\hline$<1$ year & & $6 / 31(19.4)$ & $2 / 42(4.8)$ & $13 / 102(12.7)$ & 15/143 (10.5) \\
\hline$\geqslant 1$ year & & 24/116 (20.7) & 16/140 (11.4) & 9/101 (8.9) & 25/241 (10.4) \\
\hline & & $p=0.176^{*}$ & $p=0.069^{*}$ & $p=0.142^{*}$ & $p=0.085^{*}$ \\
\hline
\end{tabular}

${ }^{*} \chi^{2}$ for differences between groups.

$\uparrow$ Reduced knee complaints were compared to no, unchanged, and more knee complaints. 
during the previous 12 months compared to both floor layers who had never used new the working methods and those who had used them for more than one year.

Among the floor layers who answered the questionnaire both in 2003 and in 2005, a total of 98 floor layers (46\%) reported that they had had no knee complaints during the previous 12 months in 2003, and 117 (54\%) reported that they had had knee complaints. Floor layers who reported knee complaints in 2003 also had an increased risk of reporting complaints in 2005, as shown in table 3.

The risk of having knee complaints for more than 30 days, or locking of the knees, in 2005 was more than double among floor layers who had used the new working methods for less than one year compared to those who had used them more. For the floor layers who had knee complaints in 2003, the adjusted odds ratios were OR 2.46 (95\% CI 1.03 to 5.83) for having knee complaints more than 30 days and OR 2.89 (95\% CI 1.11 to 7.5 ) for locking of the knees, in 2005.

Floor layers without knee complaints in 2003 who had used the new working methods less than one year had a higher risk of moderate to severe knee pain in 2005 (OR 2.72, 95\% CI 1.02 to 7.26) compared with floor layers who had used the new working methods one year or more. There were no differences for floor layers who already had severe knee pain in 2003 (OR $0.85,95 \%$ CI 0.38 to 1.92 ).

\section{Musculoskeletal complaints from other part of the body}

Frequency of musculoskeletal complaints during the previous 12 months are shown in table 4 for floor layers who had used the new working methods weekly or daily for at least one year, compared with those who had used them less. The results show no statistically significant differences between the groups. More floor layers who had used the new methods weekly/daily for at least one year reported reduced complaints in the low back and wrist compared to those who had used it less (low back, $16 \%$ vs $8 \%, p=0.006$; wrist, $8.5 \%$ vs $5.6 \%, p=0.301$ ). Only for elbows were more complaints reported among floor layers who had used the new methods ( $9.2 \%$ vs $6.5 \%, \mathrm{p}=0.337)$.

\section{Predictors for sustained knee complaints and reduced workability in $\mathbf{2 0 0 5}$}

Predictors for sustained knee complaints in 2005 are shown in table 5 . The statistically most significant predictor for sustained knee complaints $>30$ days during the previous 12 months in 2005 was self-reported knee complaints $>30$ days during the previous 12 months in 2003 (adjusted OR 8.31). For locking of the knee, the statistically significant predictor was locking of the knee in 2003 (adjusted OR 9.6). For moderate to severe knee pain in 2005, the only significant predictors were knee complaints $>30$ days in 2003 (adjusted OR 7.47) and reported low or no use of new working methods weekly or daily for at least one year (adjusted OR 0.26). For all other variables (age, stress, BMI), no significant predictive results were shown. The predictors of decreased knee pain in 2005 was use of new working methods weekly or daily for one year or more (adjusted OR 0.25 ), while all other variables were not significant. The only predictor for difficulties in carrying out the work in 2005 was self-reported knee complaints >30 days in 2003 (adjusted OR 20.7).

\section{DISCUSSION}

The frequency of floor layers continuing to use the new working methods after a period of two years (compared to three months after the course) was sustained by the implementation strategy used in this study, but the use of the new methods was not spread to floor layers who had not been trained on courses. The new working methods reduced knee complaints in floor layers, and the effects were higher when they were used for more than one year. The use of the new methods did not cause other musculoskeletal complaints. The hypothesis of the study was therefore generally confirmed. However, as it was found that instruction for one third of the floor layers was not enough to spread the methods to the other floor layers in the trade, that part of the hypothesis has been rejected.

A control group was included in the study only at the twoyear follow-up in 2005. The study would have been strengthened if the control group had been included in the study (without intervention) from 2003.

The control group for the 2005 study included all floor layers in Denmark who had not participated in the courses; this should give strength to the study.

The non-responders (15\%) among the controls may have had fewer knee complaints and used the new working-methods to a lesser extent than floor layers who participated in the study.

The floor layers who participated in the courses were not randomly selected, but volunteered to participate. This may have led to a possible selection bias towards subjects who were willing to use the new working methods. It may also be the case that floor layers with knee complaints are over-represented among participants, because those who already experience work-related health problems are often the most willing to seek to reduce the causes.

Table 3 Self-reported knee complaints of floor layers who used the new working methods (by users of $\geqslant 1$ year and $<1$ year) comparing floor layers who did not report knee problems in $2003(\mathrm{n}=98)$ with those who did $(\mathrm{n}=117)$

\begin{tabular}{|c|c|c|c|c|c|c|c|c|}
\hline \multirow{3}{*}{$\begin{array}{l}\text { Knee complaints } \\
\text { in } 2005\end{array}$} & \multicolumn{4}{|c|}{ No knee complaints $2003(n=98)$} & \multicolumn{4}{|c|}{ Knee complaints $2003(n=117)$} \\
\hline & \multirow{2}{*}{$\begin{array}{l}\text { Use the new working } \\
\text { methods } \\
<1 \text { year }(n=65) \\
\geqslant 1 \text { year }(n=33)\end{array}$} & \multirow[b]{2}{*}{ n (\%) } & Unadjusted & Adjusted* & $\begin{array}{l}\text { Use the new } \\
\text { working } \\
\text { methods } \\
<1 \text { year } \\
\text { (n= }=42 \text { ) }\end{array}$ & & Unadjusted & Adjusted* \\
\hline & & & OR (95\% Cl) & OR $(95 \% \mathrm{Cl})$ & $\geqslant 1$ year $(n=75$ & ) n (\%) & OR $(95 \% \mathrm{Cl})$ & OR $(95 \% \mathrm{Cl})$ \\
\hline$>30$ days & $<1$ year & $5(15.6)$ & $1.76(0.49$ to 6.28$)$ & 2.03 (0.52 to 7.87$)$ & $<1$ year & $19(45.2)$ & $2.07(0.93$ to 4.63$)$ & 2.46 (1.03 to 5.83$)$ \\
\hline \multirow{2}{*}{$\begin{array}{l}\text { Moderate-severe } \\
\text { knee pain }\end{array}$} & $<1$ year & $13(39.4)$ & $2.32(0.93$ to 5.8$)$ & $2.72(1.02$ to 7.26$)$ & $<1$ year & $24(57.1)$ & $0.84(0.37$ to 1.83$)$ & 0.85 (0.38 to 1.92$)$ \\
\hline & $\geqslant 1$ year & $14(21.5)$ & & & $\geqslant 1$ year & $45(60.0)$ & & \\
\hline \multirow[t]{2}{*}{ Locking } & $<1$ year & $6(18.2)$ & $2.62(0.74$ to 9.35$)$ & $3.13(0.82$ to 12.0$)$ & $<1$ year & $14(33.3)$ & $2.62(1.04$ to 6.56$)$ & 2.89 (1.11 to 7.5$)$ \\
\hline & $\geqslant 1$ year & $5(7.7)$ & & & $\geqslant 1$ year & $12(16.0)$ & & \\
\hline
\end{tabular}

${ }^{*}$ Adjusted for age, BMI, self-reported stress. 
Table 4 Musculoskeletal complaints at two-year follow-up; by floor layers and their use of new working methods $(n=670)$

\begin{tabular}{lllll}
\hline \multicolumn{3}{l}{ Use of new working-methods weekly/daily for at least one year } \\
\cline { 1 - 2 } $\begin{array}{llll}\text { Complaints during the } \\
\text { previous } \mathbf{1 2} \text { months }\end{array}$ & $\mathbf{N o}(\mathbf{n}=\mathbf{5 2 5})$ & \multicolumn{1}{l}{ Yes $(\mathbf{n}=\mathbf{1 3 1})$} & \\
\cline { 2 - 2 } $\mathbf{n}(\%)$ & $\mathbf{n}(\%)$ & p Value* \\
Neck & $175(33.5)$ & $50(38.2)$ & 0.311 \\
Shoulder & $188(35.8)$ & $47(35.9)$ & 0.988 \\
Elbow & $79(15.1)$ & $23(17.7)$ & 0.472 \\
Wrist & $220(42.1)$ & $60(45.8)$ & 0.450 \\
Upper back & $131(25.2)$ & $23(17.6)$ & 0.065 \\
Low back & $331(63.5)$ & $92(70.2)$ & 0.151 \\
Hip & $76(14.6)$ & $23(17.7)$ & 0.383 \\
Feet & $85(16.3)$ & $24(18.6)$ & 0.527 \\
\hline
\end{tabular}

${ }^{*} \chi^{2}$ test for differences between groups.

\section{Evaluation of the process}

The implementation of the new working methods reported in this study succeeded as a result of a combination of several different factors. Scientific reports were written during 19962000 to demonstrate the evidence of a causal relation between the knee-straining kneeling working positions in the floor laying trade and knee osteoarthritis and other knee disorders. ${ }^{2}{ }^{6}$ These results were repeatedly presented to the floor layers and their employers, in order to develop a collective understanding about the general health problems which result from working in kneeling positions. This shared understanding contributed to good collaboration between the researchers, trade unions and training organisations, which then led to the development of new tools which were accepted by the floor layers, provision of the tools free of charge, use of local experts, the mutuality of interests and policies among employers and the employees and their unions, and widening support for health and safety initiatives; all these together have facilitated the intervention.

The most effective contributor to the intervention was probably the good collaboration between the trade union and the employers' association, combined with widespread support from the individual employers. The aim was that free-of-charge provision of the tools would motivate floor layers to participate in the courses, and to continue to apply the new methods after completion.

The two-year follow-up showed that floor layers who had participated in the courses and who began using the new working-methods immediately afterwards were able to continue using the tools, but it also showed that more courses are needed if more floor layers are to change their working methods. To ensure that the process continues within the floor laying trade, it will therefore be important to follow-up with further initiatives.

\section{Evaluation of the effects}

Experience with the new working methods

The study showed nearly the same frequency of floor layers using the new working methods in 2005 as three months after the courses. It can therefore be concluded that if floor layers do not start to use the new working methods immediately after the courses they tend not to start later. The same frequency of floor layers who used the new working methods was found among the control group in the two-year follow-up as among floor layers before participation in courses in 2003. The use of the new working methods was therefore not automatically spread to other floor layers who have not participated in a course. Overall, it may therefore be concluded that education on two-day courses where the tools are provided free of charge is

Table 5 Predictors in 2003 for risk in 2005 of knee complaints $>30$ days, locking of the knee, knee pain, decrease of pain, and difficulties in carrying out work

\begin{tabular}{|c|c|c|c|}
\hline \multirow{2}{*}{$\begin{array}{l}\text { Self-reported complaints in } 2005 \\
\text { Knee complaints }>30 \text { days during } \\
\text { previous } 12 \text { months (yes/no) }\end{array}$} & \multirow{2}{*}{$\begin{array}{l}2003 \text { predictors } \\
\text { Knee complaints }>30 \text { days } \\
\text { (in 2003) }\end{array}$} & \multicolumn{2}{|c|}{ OR (95\% CI) unadjusted OR (95\% CI) adjusted } \\
\hline & & 7.98 (3.83 to 16.6$)$ & 8.31 (3.71 to 18.6$)$ \\
\hline & $\begin{array}{l}\text { Used new working methods } \\
\text { weekly/daily during } 1 \text { year or more }\end{array}$ & $0.53(0.26$ to 1.10$)$ & $0.46(0.20$ to 1.06$)$ \\
\hline \multirow{3}{*}{$\begin{array}{l}\text { Locking of the knee during previous } \\
12 \text { months (yes/no) }\end{array}$} & Locking of the knee (2003) & 11.5 (4.96 to 26.7 ) & $9.60(3.75$ to 24.6$)$ \\
\hline & $\begin{array}{l}\text { Knee complaints }>30 \text { days } \\
\text { (in 2003) }\end{array}$ & $1.95(0.81$ to 4.74$)$ & 3.53 (1.67 to 7.48$)$ \\
\hline & $\begin{array}{l}\text { Used new working methods } \\
\text { weekly/daily during } 1 \text { year } \\
\text { or more }\end{array}$ & $0.38(0.14$ to 1.04$)$ & $0.39(0.16$ to 0.94$)$ \\
\hline \multirow[t]{2}{*}{$\begin{array}{l}\text { Knee pain moderate to severe/no } \\
\text { or light }\end{array}$} & $\begin{array}{l}\text { Knee complaints }>30 \text { days } \\
\text { (in 2003) }\end{array}$ & 7.47 (3.8 to 14.7$)$ & 7.45 (3.91 to 14.2$)$ \\
\hline & $\begin{array}{l}\text { Used new working methods } \\
\text { weekly/daily during } 1 \text { year or more }\end{array}$ & $0.26(0.09$ to 0.74$)$ & $0.25(0.09$ to 0.70$)$ \\
\hline \multirow[t]{2}{*}{$\begin{array}{l}\text { Decrease in knee complaints during } \\
\text { previous } 12 \text { months (yes/no) }\end{array}$} & $\begin{array}{l}\text { Knee complaints }>30 \text { days } \\
\text { (in 2003) }\end{array}$ & $1.76(0.63$ to 4.89$)$ & $1.51(0.57$ to 4.02$)$ \\
\hline & $\begin{array}{l}\text { Used new working methods } \\
\text { weekly/daily during } 1 \text { year or more }\end{array}$ & $0.26(0.09$ to 0.74$)$ & $0.25(0.09$ to 0.70$)$ \\
\hline \multirow{4}{*}{$\begin{array}{l}\text { Difficulties in carrying out work } \\
\text { because of knee troubles } \\
\text { (often or daily/no or seldom) }\end{array}$} & $\begin{array}{l}\text { Knee complaints }>30 \text { days } \\
\text { (in 2003) }\end{array}$ & 20.7 (2.37 to 180.3$)$ & $24.4(3.08-193.2)$ \\
\hline & Locking of the knee & $3.06(0.84$ to 11.2$)$ & $4.04(1.2$ to 13.6$)$ \\
\hline & Bursitis & $1.41(0.37$ to 5.41$)$ & 4.35 (1.32 to 14.3$)$ \\
\hline & $\begin{array}{l}\text { Used new working methods } \\
\text { weekly/daily during } 1 \text { year or more }\end{array}$ & $0.36(0.07$ to 1.87$)$ & $0.33(0.07$ to 1.54$)$ \\
\hline
\end{tabular}

*Each covariate adjusted for all other factors: age, BMI, stress, use of new working methods, knee complaints $>30$ days in 2003 
the right strategy to get floor layers to implement new working methods in the trade, but it can also be concluded that it is necessary to carry out courses for the rest of the floor layers if there is a wish for the working methods to be spread throughout the trade.

This study indicates that the courses and the resultant increased use of the new working methods do diminish exposure to tasks carried out in kneeling work positions.

In an earlier study, we found that knee-straining work tasks in the floor laying trade constitute $56 \%$ of the work time. ${ }^{2}{ }^{13}$ It is possible to carry out a large part of the work tasks from an upright position by using the new working methods. In the interviews, the floor layers reported that $50-60 \%$ of these work tasks could be carried out from an upright position. By taking these reports into account, the use of the new methods can reduce the total amount of knee-straining activity from $60 \%$ to approximately $30 \%$. This level corresponds to the amount of knee-straining work activity for carpenters ${ }^{5}{ }^{13}$ or plumbers and pipe fitters. ${ }^{14}$

More than half (58\%) of the floor layers reported the new methods to be faster. These results indicate that the new working methods were to a great degree accepted for use after training and were seen as being as fast as the conventional working methods.

\section{Improvements in musculoskeletal complaints}

Knee complaints $>30$ days during previous 12 months, moderate to severe knee pain, and locking of the knee are complaints which indicate more severe knee problems. These complaints were less frequent among floor layers who had used the new working methods for more than one year compared to those who used them for less than one year. This indicates that the risk of getting severe knee disorders will decrease, but only when using the new methods for a longer period.

The floor layers reported in interviews that the greatest health problems were from the back and knees when working traditionally, and that this is the main cause of sick leave and early retirement. Floor layers reported that they need to get used to the new working methods, and that it may lead to more health problems in the beginning, but that this reduces over time. They also commented that it is important to learn correct working methods from the beginning to prevent new musculoskeletal problems. The floor layers who used the new methods weekly or daily reported that health problems are reduced in the knee, back, arms and fingers. They also got less tired, and they felt more energetic after a day's work. Some of the older floor layers reported that they now have the possibility of continuing working for more years in the trade before retirement: "Before, I was dead when I came home. I am not so tired and I have more energy and less sick leave. It is now possible to stay for a longer period in the trade".

Prior to the courses, the floor layers had been concerned about the possibility of getting more pain in their elbows and shoulders when using the new working methods. When trying to use the new working methods by moving the tool in figure-of-eight patterns, the stick was held some distance away from the body. The glue and filling is thick, and the strength which was needed to distribute it in an equal layer particularly affects the elbows, shoulders and wrist. The courses have therefore focused on correct working methods to prevent musculoskeletal problems occurring especially in the wrist, elbow, shoulder and back. The floor layers were instructed to go backwards and forwards, while they held the stick close in front of the trunk. The strain on the body resulting from these working methods was not measured, and it is therefore not yet possible to document whether this method leads to less strain than other methods.

Long-term effects on the musculoskeletal system cannot be determined from our results. Some floor layers working with the new methods reported worse pain in elbows, but the differences were not statistically different. The explanation may be that the new working methods are more strenuous to the elbows, especially if the floor layers are not following the correct ergonomic procedures. Another explanation could be that floor layers with elbow problems will tend to change working methods to a greater extent. This is supported in the questionnaire and in the interviews where floor layers reported reduced pain when changing to new working methods.

Even though they had changed their working methods, there were still many elbow and wrist-straining work tasks (for example, use of knives for cutting linoleum or carpets) which could be continuing causes of musculoskeletal problems. Floor layers may also use the conventional working method some of the time if they are only using the new methods weekly. It is therefore necessary to follow the process closely to ensure that the right working procedures are used to avoid future problems.

Even for those floor layers who had only used the new working methods weekly, the results in this study showed a reduced frequency of knee complaints.

The most significant predictor for sustaining self-reported knee complaints >30 days in 2005 was knee complaints $>30$ days in 2003. The predictor for sustaining locking of the knee in 2005 was locking of the knee in 2003. All other factors were not significant. The only influential predictor for decrease in knee pain was use of the new working methods. This supports the suggestion that for those who already have more severe knee disorders, the troubles will decrease, but not disappear, when working methods are changed. Floor layers must therefore be encouraged to start using new working methods as early as possible, before getting health problemspreferably in the apprenticeship period.

\section{CONCLUSION}

The use of training on courses which included the active participation of the trade union and employers' association was a success, because $82 \%$ of floor layers were still using the new working methods (38.4\% weekly or daily) two years after implementation. The two-year follow-up showed that floor layers who had participated in courses and who started to use the new working methods immediately afterwards continued to use them. The new working methods appeared to result in a reduced risk of developing more severe knee disorders, and of reducing the degree of knee pain in the floor layers who already had knee problems. The reduction in severe knee complaints was greatest if floor layers began using the new working methods before they developed knee problems. More floor layers with knee troubles change methods, which may increase their possibility of staying in work as a floor layer. The new working methods do not cause musculoskeletal health problems in the neck, shoulder or arms but it is necessary to follow the process closely to prevent problems-especially in the wrists and elbows. More courses are needed if skilled and apprentice floor layers are to change their working methods. To ensure that the process continues within the floor laying trade it will therefore be important to follow-up with further initiatives from the trade organisations (more courses, agreement with the employers to deliver new tools free of charge, and obligatory training courses and new tools free of charge for apprentice floor layers). 


\section{Main messages}

- An implementation strategy consisting of several different factors (information, education, collaboration between employers and trade union, developing of new tools, provision of tools free of charge, training at courses by use of local experts) has been effective in introducing new working methods in the floor laying trade.

- Floor layers who had participated in courses and who began to use the tools immediately afterwards were able to continue using the tools. The new working methods appear to result in a reduced risk of developing severe knee disorders, and of reducing the degree of knee pain in floor layers who already had knee pain, especially in those who began using the new working methods before they developed knee problems. The new working methods did not cause musculoskeletal health problems in other part of the musculoskeletal system.

- This implementation strategy may also succeed in other trades in the construction industry, but it takes time and requires very good collaboration between the employers and trade union.

\section{Policy implications}

- As a result of this study the two-day training courses have now been included in the education of all apprentice floor layers in Denmark. New floor layers now have the new tools free of charge as a part of their apprenticeship.

- A course including free new tools is now offered to all skilled floor layers.
Acknowledgements: The study was supported by The Danish foundation "Sygekassernes Helsefond" (Sick-Benefit Association Foundation)

Competing interests: None declared.

\section{REFERENCES}

1. Ekström H, Engholm G, Nyqvist B, et al. Knäbesvär som arbetsmedicinskt problem [Knee disorders as an occupational problem]. Stockholm: Bygghälsans Forskningsstiftelse, 1983

2. Jensen L, Mikkelsen S, Loft I, et al. Work-related knee disorders in floor layers and carpenters. J Occup Environ Med 2000;42:835-42.

3. Kivimäki J, Riihimäki H, Hänninen K. Knee disorders in carpet and floor layers and painters. Scand J Work Environ Health 1992:18:310-16.

4. Thun M, Tanaka S, Smith AB, et al. Morbidity from repetitive knee trauma in carpe and floor layers. $\mathrm{Br} \mathrm{J}$ Ind Med 1987;44:611-20.

5. Holmström E, Mortiz U, Engholm G. Musculoskeletal disorders in construction workers. Occup Med 1995;10:295-312.

6. Jensen L, Mikkelsen S, Loft I, et al. Radiographic knee osteoarthritis in floorlayers and carpenters. Scand J Work Environ Health 2000;26:257-62.

7. Jensen L, Kofoed L. Musculoskeletal disorders among floor layers: Is prevention possible? Appl Occup Environ Hyg 2003:17:797-806.

8. De Jong A, Vink P. Participatory ergonomics applied in installation work. App/ Ergon 2002;33:439-48.

9. Schneider F. Four steps to an effective office ergonomics program. Occup Health Saf 2001;70:140-4.

10. van der Molen H. Evidence-based implementation of ergonomic measures in construction work. Amsterdam, the Netherlands: Thesis Coronal Institute of Occupational and Environmental Health, Research Institute Am COGG. Arbouw, the National Occupational Health and Safety Institute in the Dutch construction industry, 2005.

11. Jensen LK, Friche $\mathrm{C}$. Effects of training to implement new tools and working-methods to reduce knee load in floor layers. Appl Ergon 2007; 38:655-65

12. Kuorinka I, Jonsson B, Kilbom A, et al. Standardised Nordic questionnaires for the analysis of musculoskeletal symptoms. App/ Ergon 1987;18:233-7.

13. Jensen L, Eenberg W, Mikkelsen S. Validity of self-reporting and video-recording for measuring knee-straining work postures. Ergonomics 2000;43:310-16.

14. Eenberg W, Nielsen J, Mikkelsen KL, et al. Arbejdsrelateret knæbesvær, psykosocialt arbejdsmiljø, arbejdsevne og afgangsårsager blandt blik- og rørarbejdere /Workrelated knee-troubles, psychosocial work environment, work capacity and causes of retirement among plumbers and pipelayers]. Copenhagen. Denmark: Arbejdsmiljøinstituttet, 2002

\section{BNF for Children 2006, second annual edition}

In a single resource:

- guidance on drug management of common childhood conditions

- hands-on information on prescribing, monitoring and administering medicines to children

- comprehensive guidance covering neonates to adolescents

For more information please go to bnfc.org. 